\title{
MAY SCHISTOSOMIASIS HAEMATOBIUM AND MANSONI LEAD TO INFERTILITY IN THE HOST?
}

\author{
By \\ HEBA ABDEL KADER AMINOU AND AYMAN NABIL IBRAHIM \\ Department of Parasitology, Faculty of Medicine, Ain-Shams University Cairo 11566, \\ Egypt ( ${ }^{*}$ Correspondence: hebaaminou74@hotmail.com, Mob: 01001550924)
}

\begin{abstract}
Schistosomiasis is worldwide water-borne infectious risky disease. Steroid hormones are synthesized from cholesterol in adrenal glands and gonads. They include corticosteroids, androgens, estrogens and progestogens. The present study evaluated the effect of Schistosoma mansoni and S. haematobium infections on the hamsters' fertility as indicated by the changes of steroid sex hormones levels. Eighteen Mesocricetus auratus clear laboratory bred hamsters (9 males \& 9 females) were divided into 3 groups. G1: was infected with $S$. mansoni cercariae, G2: was infected with $S$. haematobium cercariae, and G3: was not infected (negative control). The results showed that testosterone level increased in all infected hamsters but markedly increased in those infected with schistosomiasis haematobium $(7.52 \& 0.78 \mathrm{nmol} / \mathrm{L})$ as compared to control $(2.41 \&$ $0.341 \mathrm{nmol} / \mathrm{L}$ ). Progesterone level decreased in all infected hamsters especially in $S$. mansoni and S. haematobium females $(5.732 \& 11.13 \mathrm{nmol} / \mathrm{L})$ in comparison to control $(86.34 \&$ $64.7 \mathrm{nmol} / \mathrm{L})$. Estradiol E2 level markedly decreased in female hamsters infected with either $S$. mansoni or S. haematobium (247.54 \& 463.8pmol/L) as compared to control $(1658 \mathrm{pmol} / \mathrm{L})$ but not detected in male hamsters.
\end{abstract}

Keywords: Schistosoma species, Hamsters, Testosterone, Estradiol, Progesterone, Infertility.

\section{Introduction}

Schistosomiasis is a major neglected tropical disease that affects more than 250 million people worldwide (Val et al, 2017). Schistosomiasis haematobium and mansoni are serious public health problem in tropical and subtropical regions (Calasans et al, 2018), particularly in rural agricultural areas with limited access to clean water (Oliveira et al, 2019).

Neuroimmunoendocrine host-parasite interactions are very complex and involve hormones, cytokines, chemokines and neuropeptides which play important roles in these interactions. These systems are connected by a complex network in which the immune response of the host to the parasite is modulated by many hormones (Hernández-Bello et al, 2010).

Habib et al. (2010) reported a relation between schistosomiasis and hormonal changes. Delmondes et al. (2014) found an association between schistosomiasis and infertility, which occurred due to formation of egg granuloma in reproductive organs. Woodall and Kramer (2018) reported that S. hae- matobium infection in female may lead to infertility. Abdel-Naser et al. (2019) suggested that schistosomiasis may lead to male infertility due to hormonal imbalance, damage of testicular tissue or genital ducts obstruction. Ribeiro et al. (2019) concluded that tbasic hormonal mechanisms can lead to the discovery of entirely novel anthelmintic interventions against schistosomiasis.

The present study aimed to evaluate the effect of Schistosoma mansoni and S. haematobium infection on hamsters' fertility by studying the changes of steroid sex hormones levels.

\section{Materials and Methods}

Animals, parasites and infection: Schistosoma mansoni and Schistosoma haematobium was purchased from the Schistosome Biological Supply Centre (SBSC), Theodor Bilharz Research Institute (TBRI), Giza, Egypt. A total of 18 Mesocricetus auratus hamsters (9 males \& 9 females) were divided in three groups each of three males and three females. G1: was infected with $S$. mansoni cercariae, G2: was infected with $S$. haematobium cercariae, and G3: was not 
infected (negative control). Stool and urine examinations were used to prove the hamsters' infection with $S$. haematobium and $S$, mansoni.

Infection was done percutaneously with 350-400 Schistosoma cercariae/hamster. 1112 weeks later, orbital sinus blood sample was collected under general anesthesia. Hamster was scuffed with thumb and forefinger of the non-dominant hand and skin around the eye was pulled taut. A capillary tube was inserted into eye medial canthus at 30 degree angle to nose. Slight thumb pressure was enough to puncture tissue, enter the plexus/sinus and blood was put into the capillary tube. Once the required blood volume was collected, the capillary tube was gently removed and wiped with sterile cotton. Bleeding if occurred was stopped by gentle finger pressure (Parasuraman et al, 2010).

Hormone serum levels: Estradiol, testosterone and progesterone hormones levels in sera were measured using an electrochemiluminescence immunoassay (ECLIA) with Cobas e411 Analyser (Roche Diagnostics, USA), according to manufacturer instructions. ECLIA is a competitive test using two monoclonal antibodies. Endogenous sex hormones released from sample compete by adding hormone derivative labeled with a ruthenium complex for the binding sites on the biotinylated antibody. The reaction mixture was aspirated into the measuring cell where the microparticles were magnetically captured onto the electrode surface. Unbound substances were removed with ProCell/ProCell M. Application of an electrode voltage induced chemiluminescent emission which was measured by a photomultiplier.

Statistical analysis: Data were coded, tabulated, and statistically analyzed using IBM SPSS statistics (Statistical Package for Social Sciences) software version 18.0, IBM Corp., Chicago, USA, 2009. Descriptive statistics were done for quantitative data as minimum and maximum of the range as well as $\mathrm{M} \pm \mathrm{SD}$ (standard deviation). Inferential analyses were done using Shapiro-Wilk test for normality testing and ANOVA test with post hoc Tukey's test. The $\mathrm{P}$ value $<0.050$ was significant.

\section{Results}

Testosterone level increased in infected male and female hamsters, markedly in $S$. haematobium infected males (7.22 \pm 0.27 $\mathrm{nmol} / \mathrm{L})$. Progesterone level decreased in all infected hamsters, markedly in $S$. mansoni and $S$. haematobium females $(5.9 \pm 0.5 \&$ $10.9 \pm 2.7 \mathrm{nmol} / \mathrm{L}$, respectively). Estradiol E2 level markedly decreased in females infected with both $S$. mansoni and $S$. haematobium $(252.3 \pm 29.3 \quad \& \quad 467.9 \pm 21.6 \mathrm{pmol} / \mathrm{L})$. while in male hamsters, level was not detectable $(18.4 \mathrm{pmol} / \mathrm{L})$. Details were given in table (1) and figures $(1,2,3,4 \& 5)$.

\begin{tabular}{|c|c|c|c|c|c|c|}
\hline Hormone & Sex & Group & $\mathrm{M} \pm \mathrm{SD}$ & Range & $\mathrm{p}$ & $\mathrm{HG}$ \\
\hline \multirow{6}{*}{ 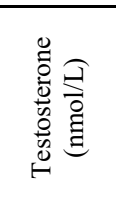 } & \multirow{3}{*}{$\frac{0}{\Sigma^{\pi}}$} & S. mansoni & $5.35 \pm 0.99$ & $4.23-6.12$ & \multirow{3}{*}{$\begin{array}{l}* \\
\stackrel{*}{\circ} \\
\dot{0} \\
\dot{0}\end{array}$} & $\mathrm{a}$ \\
\hline & & S. haematobium & $7.22 \pm 0.27$ & $6.98-7.52$ & & B \\
\hline & & Non-infected & $2.42 \pm 0.48$ & $1.95-2.90$ & & $\mathrm{c}$ \\
\hline & \multirow{3}{*}{ 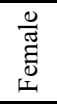 } & S. mansoni & $0.50 \pm 0.26$ & $0.27-0.79$ & \multirow{3}{*}{ ?ִ } & A \\
\hline & & S. haematobium & $0.69 \pm 0.23$ & $0.43-0.87$ & & A \\
\hline & & Non-infected & $0.40 \pm 0.36$ & $0.08-0.79$ & & A \\
\hline \multirow{6}{*}{ 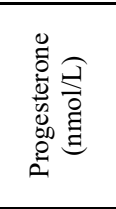 } & \multirow{3}{*}{$\sum_{\Sigma}^{\frac{0}{\pi}}$} & S. mansoni & $41.8 \pm 10.0$ & $31.7-51.6$ & \multirow{3}{*}{ 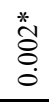 } & $\mathrm{a}$ \\
\hline & & S. haematobium & $66.6 \pm 6.3$ & $59.5-71.7$ & & $\mathrm{~B}$ \\
\hline & & Non-infected & $86.8 \pm 8.5$ & $78.5-95.5$ & & $\mathrm{~B}$ \\
\hline & \multirow{3}{*}{ 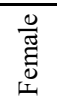 } & S. mansoni & $5.9 \pm 0.5$ & $5.4-6.4$ & \multirow{3}{*}{$\begin{array}{l}* \\
\\
\\
\dot{8} \\
\dot{0}\end{array}$} & A \\
\hline & & S. haematobium & $10.9 \pm 2.7$ & $8.1-13.5$ & & A \\
\hline & & Non-infected & $64.8 \pm 5.3$ & $59.5-70.1$ & & $\mathrm{~B}$ \\
\hline \multirow{6}{*}{ 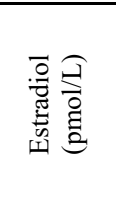 } & \multirow{3}{*}{$\frac{0}{\sum^{\pi}}$} & S. mansoni & & & \multirow{3}{*}{\multicolumn{2}{|c|}{$\begin{array}{l}\text { Could not } \\
\text { be calcu- } \\
\text { lated }\end{array}$}} \\
\hline & & S. haematobium & & & & \\
\hline & & Non-infected & & & & \\
\hline & \multirow{3}{*}{ 胥 } & S. mansoni & $252.3 \pm 29.3$ & $225.7-283.7$ & \multirow{3}{*}{$\begin{array}{l}\text { * } \\
\text { ¿ } \\
0 \\
0\end{array}$} & $\mathrm{a}$ \\
\hline & & S. haematobium & $467.9 \pm 21.6$ & $448.6-491.2$ & & $\mathrm{a}$ \\
\hline & & Non-infected & $1902.3 \pm 682.1$ & $1376.0-2673.0$ & & $\mathrm{~b}$ \\
\hline
\end{tabular}




\section{Discussion}

Schistosomes infect more than 250 million people in 74 countries worldwide in the endemic areas of Africa, Eastern Asia, Central America, the Caribbean, South America, and the Middle East (Gryseels et al, 2006). Steroid hormones are synthesized from cholesterol in the adrenal glands and gonads. These include corticosteroids, androgens, estrogens and progestogens (Frye, 2009).

Many studies revealed that parasites can change the hormonal microenvironment to favor their growth and reproduction. Added to their capability to actively evade immune responses, parasites can also evolve structures similar to steroid hormone receptors that can bind to hormone metabolites produced by the host (Escobedo et al, 2005).

In this study, we are aiming to investigate the effect of schistosomiasis mansoni and haematobium on the fertility of the host by studying the changes of the levels of steroid sex hormones in infected male and female hamsters.

Testosterone is the primary male sex hormone that plays a key role in the development of male reproductive tissues such as testes and prostate (Mooradian et al, 1987). The results of the present work showed increased testosterone level in all infected hamsters (male and female) in comparison to non-infected ones. This agreed with Abdallah et al, (1994) who detected an increase in serum levels of testosterone in both $S$. mansoni infected males and females. Oliveira et al. (2019) reported increase of testosterone level in male hamsters infected with $S$. mansoni, while it decreased in females. These results are in contrast with those obtained by $\mathrm{He}$ et al, (2000) who found that infection with $S$. japonicum led to a decrease in testosterone levels in the serum of male mouse, and Marzouki and Amin, (1997) who found that schistosomiasis mansoni causes a decrease in testosterone level, while serum levels of gonadotropins (FSH, LH) showed no significant changes. Besides, Ashby et al, (2012) reported that in- creased testosterone levels could be the cause of infertility associated with S.mansoni and haematobium infections.

Progesterone is an endogenous steroid and progestogen sex hormone involved in the menstrual cycle, pregnancy, and embryogenesis of humans and other species (Patel et al, 2015).

The results of the present work also showed that progesterone level decreased in all infected hamsters but markedly decreased in female hamsters infected with both Schistosoma mansoni and haematobium $(5.732 \& 11.13 \mathrm{nmol} / \mathrm{L})$ in comparison to non-infected hamsters (86.34 and 64.7 $\mathrm{nmol} / \mathrm{L})$. This agreed with Oliveira et al, (2019) who reported that $S$. mansoni infection caused a decrease of progesterone levels in hamsters. But, Abdallah et al, (1994) detected an increase in progesterone level in both $S$. mansoni infected males and females.

To diagnose fertility, progesterone level is measured to assess ovulation and luteal phase (Guillaume et al, 1987). Progesterone has a role in regulation of sperm functions such as capacitation and motility. If sperms lose their acrosomes before binding to oocyte, they become unable to bind to zona pellucida and thereby, to fertilize (Shah et $a l, 2003)$. Hence, the reduction of progesterone levels shown by the present study could be a cause of infertility associated $S$. mansoni and $S$. haematobium infection, both in females and males.

Ovary is the organ responsible for the production of estrogens (the most active of which is $17 \beta$-estradiol. Estrogens are responsible for maturation of vagina and uterus and have a role in ovarian function. Therefore, estrogens play an important role in female fertility (Ryan, 1982).

The present results showed that estradiol E2 level markedly decreased in female hamsters infected with Schistosoma mansoni and S. haematobium $(247.54 \& 463.8 \mathrm{pmol} / \mathrm{L})$ in comparison to non-infected female hamsters $(1658 \mathrm{pmol} / \mathrm{L})$. This agreed with Wang et al, (2001) who found that schistosome infection 
may suppress estradiol and progesterone secretion, decrease the rate of pregnancy and it may also increase the complications and mortality during the gestation periods. Santos et al, (2014) revealed in their study that infection with $S$. haematobium may lead to infertility in females. Oliveira et al. (2019) detected a significant decrease in estradiol in hamsters infected with $S$. mansoni.

\section{Conclusion}

Schistosomiasis mansoni and haematobium may lead to infertility in male and female hosts by affecting levels of steroid sex hormones; testosterone, progesterone and estrogen. Studying physiological and molecular mechanisms involved in complex hormonal host-parasite relationship are ongoing and will be published in due time elsewhere

Ethical consideration: The study was approved by the Research Ethics Committee, Faculty of Medicine, Ain Shams University, FWA 00006444. Animals were dealt with according to the national regulations for the Animal Ethics rules, Ain-Shams University.

Declarations: Authors declared that they neither have any interest nor received fund.

\section{References}

Abdalla, KF, Abdel-Aziz, SM, el Fakahany, A F, el-Hamshary, AS, Afifi, LM, 1994: Effect of praziquantel on sex hormone levels in murine schistosomiasis mansoni. J. Egypt. Soc. Parasitol. 24, 3:627-32.

Abdel-Naser, MB, Altenburg, A, Zouboulis, C C, Wollina, U, 2019: Schistosomiasis (bilharziasis) and male infertility. Andrologia 51, 1: e13165. doi: 10.1111/and.13165.

Ashby, HL, Gama, RM, Sur, H, Inglis, J, Ford, C, et al, 2012: Hypergonadotrophic hypogonadism due to testicular adrenal rest tumours presenting with hypogonadotrophic hypergonadism. Ann. Clin. Biochem. 49, 5:497-9.

Calasans, TAS, Souza, GTR, Melo, CM, Madi, RR, Jeraldo, VLS, 2018: Socioenvironmental factors associated with Schistosoma mansoni infection and intermediate hosts in an urban area of northeastern Brazil. PLoS One 2;13(5). https://doi.org/10.1371/journal.pone.0195519

Delmondes, LM, Cruz, MA, Guimarães, MK, Santana, LG, Gonçalves, VP, et al, 2014: Endocervical schistosomiasis: Aase report. Rev.
Bras. Ginecol. Obstet. 36, 6:276-80.

Escobedo, G, Roberts, CW, Carrero, JC, Morales-Montor, J, 2005: Parasite regulation by host hormones: An old mechanism of host exploitation. Trends Parasitol. 21, 12:588-93.

Frye, CA, 2009: Steroids, reproductive endocrine function, and affect: A review. Minerva Ginecol. 61, 6:541-62.

Gryseels, B, Polman, K, Clerinx, J, Kestens, L, 2006: Human schistosomiasis. Lancet 368, 9541:1106-18.

Guillaume, J, Benjamin, F, Sicuranza, B, Wang, CF, Garcia, A, et al, 1987: Maternal serum levels of estradiol, progesterone and h-Choriongonadotropin in ectopic pregnancy and their correlation with endometrial histologic findings. Surg. Gynecol. Obstet. 165:9-12.

Habib, FA, Zaki, MM, El-Aal, AA, Safwat, M D, Domiaty, MA, 2010: Immunohistochemical expression of oestrogen and progesterone receptors during experimental acute and chronic murine schistosomiasis mansoni. Rev. Soc. Bras. Med. Trop. 43, 5:531-5.

He, HB, Ohta, N, Kawaguchi, H, 2000: Effect of Schistosoma japonicum infection on serum testosterone levels in mice. Zhongguo Ji Sheng Chong Xue Yu Ji Sheng Chong Bing Za Zhi. 18, 3:173-5.

Hernández-Bello, R, Escobedo, G, Guzmán, C, Ibarra-Coronado, EG, López-Griego, L, et al, 2010: Immunoendocrine host-parasite interactions during helminth infections: from the basic knowledge to its possible therapeutic applications. Parasite Immunol. 32, 9/10:633-43.

Marzouki, ZM, Amin, AM, 1997: The effect of Schistosoma mansoni infection on testicular lipid in mice. J. Egypt. Soc. Parasitol. 27, 2:58195.

Mooradian, AD, Morley, JE, Korenman, SG, 1987: Biological actions of androgens. Endocr. Rev. 8, 1:1-28.

Oliveira, KC, Cardoso, R, Santos, ACD, Fernandes, R, Botelho, MC, 2019: Imbalance of steroid hormones in hamsters infected with $S c h$ istosoma mansoni. Endocr. Metab. Immun. Dis.

Drug Targ. 29. https://doi.org/ 10.2174/1871530 $\underline{319666190529121204}$

Parasuraman, S, Raveendran, R, Kesavan, R, 2010: Blood sample collection in small laboratory animals. J. Pharmacol. Pharmacother. 1, 2:8793.

Patel, B, Elguero, S, Thakore, S, Dahoud, W, Bedaiwy, M, Mesiano, S, 2015: Role of nuclear 
progesterone receptor isoforms in uterine pathophysiology. Hum. Reprod. 21, 2:155-73.

Ryan, KJ, 1982: Biochemistry of aromatase: significance to female reproductive physiology. Cancer Res. 42, 8:S3342-4.

Santos, J, Gouveia, MJ, Vale, N, Delgado, L, Gonçalves, A, et al, 2014: Urinary estrogen metabolites and self-reported infertility in women infected with Schistosoma haematobium. PLoS One21, 9, 5. https://doi.org/10. 1371/ journal. pone. 0096774

Ribeiro, AR, Luis, C, Fernandes, R, Botelho, MC, 2019: Schistosomiasis and Infertility: What Do We Know? Trends Parasitol.35, 12:964-71. Shah, C, Modi, D, Gadkar, S, Sachdeva, G,
Puri, C, 2003: Progesterone receptors on human spermatozoa. Indian J. Exp. Biol. 41, 7:773-80.

Vale, N, Gouveia, MJ, Rinaldi, G, Brindley, P J, Gartner, F, Correia da Costa, JM, 2017: Praziquantel for schistosomiasis: Single-drug metabolism revisited, mode of action, and resistance. Antimicrob. Agents. Chemother. 61: e02582-16.

Wang, YN, Ma, XM, Li, H, Zhang, XY, Huang, WC, 2001: Effect of experimental infection with Schistosoma japonicum on the pregnancy of mice. Bing Za Zhi. 19, 4:233-5.

Woodall, PA, Kramer, MR, 2018: Schistosomiasis and Infertility in East Africa. Am. J. Trop. Med. Hyg. 98, 4:1137-44.

\section{Explanation of figures}

Fig. 1: Serum testosterone among male groups

Fig. 2: Serum testosterone among female groups

Fig. 3: Serum progesterone among male groups

Fig. 4: Serum progesterone among female groups

Fig. 5: Serum estradiol among female groups

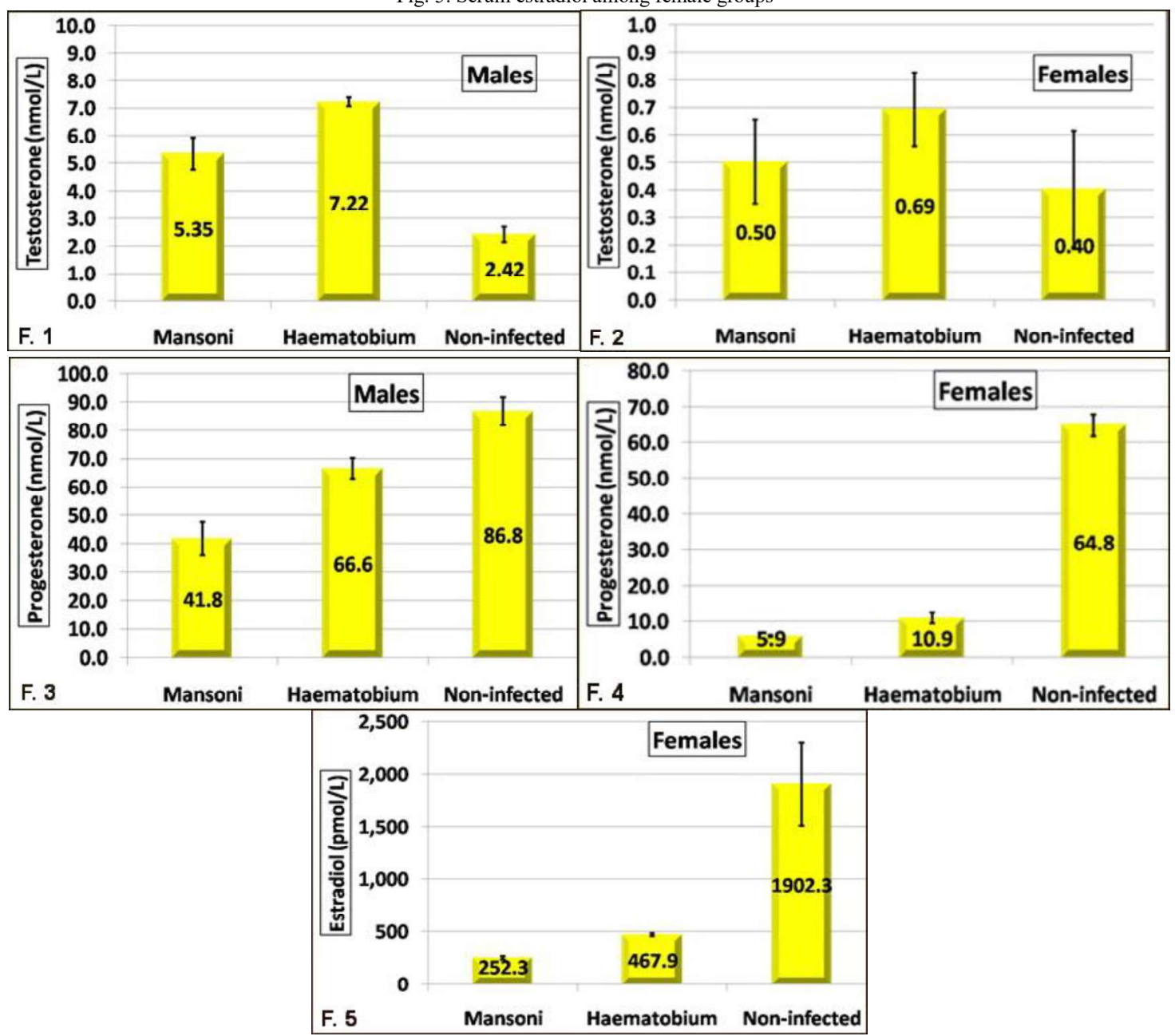

